\title{
O AGIR COMUNICATIVO NA CONSTRUÇÃO DO CONHECIMENTO EM ENFERMAGEM
}

Suzana Rodrigues do Nascimento* Marta Lenise do Prado**

\section{Resumo}

Trata-se de um ensaio teórico com o objetivo de propor o uso da teoria do agir comunicativo do filósofo Jürgen Habermas, como mediador das tecnologias educacionais na construção do conhecimento em Enfermagem. A partir das contribuições do filósofo e de autores como Demo, Morin, Assman, Perrenoud, Waldow, Ramos, entre outros, refletimos sobre os avanços tecnológicos e as inovações necessárias na área da educação em Enfermagem. Acreditamos que esta proposta possa contribuir para a implantação das diretrizes curriculares nacional dos cursos de graduação.

Descritores: educação em enfermagem; filosofia em enfermagem

\begin{abstract}
It is a theoretical essay aiming at proposing the usage of the communicative action theory, by philosopher Jürger Habermas, as a mediator of educational technologies in building nursing knowledge. Based on the contributions by the philosopher and authors such as Demo, Morin, Assman, Perrenoud, Waldow, and Ramos, we reflect on technological advances and the necessary innovations in the field of nursing education. We believe that this proposal can contribute to implementing the national curriculum guidelines in undergraduate courses. Descriptors: nursing education; philosophy in nursing

Title: Communicative action for building nursing knowledge
\end{abstract}

\begin{abstract}
Resumen
Se trata de un ensayo teórico que propone el uso de la teoría de la acción comunicativa del filósofo Jürgen Habermas, como mediadora de las tecnologías educativas en la construcción del conocimiento en Enfermería. A partir de las contribuciones del filósofo y de autores como Demo, Morin, Assman, Perrenoud, Waldow y Ramos hacemos una reflexión sobre los avances tecnológicos e innovaciones necesarias en el campo de la educación en Enfermería. Creemos que la propuesta pueda contribuir para implantar las directrices curriculares nacionales de los cursos de graduación.

Descriptores: educación en enfermería; filosofía en enfermería

Titulo: La acción comuncativa en la construcción del conocimiento en enfermería
\end{abstract}

\section{Introdução}

Avanços tecnológicos e a globalização desencadearam transformações na sociedade brasileira atual e, consequentemente, no ensino superior. Essas transformações geraram novas maneiras de viver e de educar, além de demandas do cotidiano, seja o desfrutar dos benefícios, seja o enfrentar dificuldades que as permeiam, como falta de oportunidades e exclusão social.

Especificamente na Enfermagem o ensino superior vive um momento de construção e vivência de um novo modelo pedagógico quando universidade, serviço e comunidade estão envolvidas. Essa afirmação convida a pensar que o envolvimento de Universidade (docentes e alunos) com a realidade em que o trabalho ocorre, aliados à construção do conhecimento, pode ser importante, pois extrapola os limites da escola e revela uma nova visão do ensino-aprendizagem ${ }^{(1)}$.

O desenvolvimento científico-tecnológico traz à tona questões relativas às transformações sociais, constrói novos padrões de comportamento em todas as áreas, altera a forma de organização do trabalho docente, influenciando significativamente a educação e incentivando a compreensão da utilização das tecnologias como instrumentos pedagógicos.

Desta forma, discute-se nesse material a construção do conhecimento na Enfermagem entrelaçada por aspectos comunicacionais essenciais na prática profissional. Ampliamse essas reflexões para aspectos da comunicação na educação com base nas contribuições do agir comunicativo de Jürgen Habermas.

Para isso, busco em vários autores, elementos que subsidiem esse ensaio. A proposta de levar o agir comunicativo ao conhecimento de todos os envolvidos no ensino de Enfermagem, possibilitará enfrentar os desafios do novo milênio e seus impactos na saúde, de modo a buscar a emancipação do futuro profissional. Isso, é o que propõe as Diretrizes
Curriculares, um ensino capaz de despertar o futuro profissional para sua atuação diante das demandas sociais, unindo além da necessidade da capacitação docente, como elo fundamental do processo de construção do conhecimento, o projeto pedagógico capaz de envolver e preparar o aluno para agir por meio da comunicação, buscando o consenso na resolução de problemas.

\section{A técnica e a tecnologia}

Os avanços tecnológicos impulsionados pela globalização estimularam vários setores. Para Vieira "A globalização redimensionou as noções de espaço e tempo; notícias dão a volta ao mundo, capitais entram e saem de um país por transferências eletrônicas, novos produtos são fabricados ao mesmo tempo em muitos países e em nenhum deles isoladamente. Fenômenos globais influenciam fatos locais e vice-versa."(2:71)

A tecnologia é entendida como uma arte, um conhecimento dos instrumentos, o que dependa da sua elaboração, da sua criação, da sua utilização apropriada e da maneira de se servir deles; enquanto a técnica corresponde, unicamente, à maneira de se servir dos instrumentos(3).

Em meio a esses avanços, os profissionais de Enfermagem têm realizado esforços no sentido de adaptar-se aos ambientes onde a tecnologia se faz presente, porque isso requer do profissional atualização, visão crítica e reflexiva do trabalho. Ao mesmo tempo, esses profissionais têm se beneficiado dos recursos tecnológicos disponíveis, convertendoos conforme a realidade vivida, em cuidado de qualidade, capaz de proporcionar ao indivíduo uma recuperação plena, sem considerá-la, no entanto, recurso primordial(4).

Da mesma maneira que na saúde, a tecnologia tem sido tema de interesse e preocupação na educação, no sentido de otimizar sua utilização para favorecer o conhecimento. A atualização requerida do profissional inclui pensar a tecnologia

\footnotetext{
* Enfermeira. Mestre em Tecnologia - CEFET. Doutoranda em Filosofia de Enfermagem- UFSC. Docente de Enfermagem - UFPR. Membro do GEMSA ${ }^{\star \star}$ Enfermeira. Doutora em Enfermagem -UFSC. Docente de Enfermagem/UFSC. Membro do GIATE.

E-mail do autor: srnascimento@matrix.com.br
} 
não apenas como uso de materiais e equipamentos, visualizada em parceria às didáticas e métodos de ensino adotados para a construção do conhecimento. Assim, podemos dizer que mais do que materiais e equipamentos para lecionar, as tecnologias são o meio de aproximar o docente e aluno, convidando-os a descobertas. Estas, submetidas a um processo de reflexão e análise, geram conhecimentos para a Enfermagem, de forma integrada entre o pensar e o fazer, resultando não apenas em ação ou procedimento técnico, mas em inovação. No entanto, como inserir as novas tecnologias na educação, sem limitar a criatividade e visão crítica? O agir comunicativo, pode mediar uma comunicação efetiva no uso dessas tecnologias, permitindo que professor e aluno sejam membros ativos, participantes.

\section{0 agir comunicativo como mediador educacional}

Para apresentar a comunicação, recorremos ao pensamento habermasiano no que concerne ao agir comunicativo, a fim de subsidiar a discussão sobre a construção do conhecimento na Enfermagem como prática social e sugerir uma comunicação pautada em suas idéias.

O agir comunicativo pode ser explicado como a capacidade de falar e agir. No processo educacional transpõe o conceito de comunicação para revelar a relação necessária entre os sujeitos. Consiste na interação entre sujeitos que como tal se compreendem ${ }^{(5)}$.

O processo de comunicação entre indivíduos com base no agir comunicativo revela uma relação marcada pelo consenso das idéias, caracterizando o que o filósofo Jürgen Habermas denomina relação intersubjetiva. A ação comunicativa consiste na prática da argumentação, reflexão e entendimento, buscando a libertação da coerção e da imposição de idéias, que impedem a criatividade e o conhecimento crítico. A agir comunicativo pode ser caracterizado como um tipo de ação social que, através da intersubjetividade, visa à autonomia.

Além disso, provoca a intersubjetividade, a qual para que aconteça, necessita envolvimento e interesse dos indivíduos na comunicação; os participantes estabelecem um equilíbrio em suas atitudes e tentam atingir seus objetivos mediante um acordo existente entre os mesmos; buscam o entendimento mútuo por meio da coordenação das ações. O momento de encontro das pessoas é uma parcela da vida recortada em vista de uma temática. Nesse aspecto, a situação de ação é, uma situação de fala na qual os agentes assumem alternadamente os papéis comunicacionais de falantes, e destinatários ${ }^{(5)}$.

No agir comunicativo é preciso que os participantes possuam um ponto em comum, isto é, entendam-se acerca de algo no mundo. Nessa comunicação, a representação de fatos é uma das formas de entendimento, e os atos de fala, que representam estados e acontecimentos, produzem relações interpessoais e manifestação de vivências.

No ato comunicativo, falantes e ouvintes em busca do entendimento ocorrem num sistema composto pelo mundo objetivo, onde se dão os acontecimentos, um mundo social, onde ocorrem as relações interpessoais e o mundo subjetivo, onde se passam as vivências.

Para isso, os atores participantes da ação comunicativa devem considerar três funções da linguagem. A primeira, função representativa ou cognitiva (deriva dos atos de fala constativos), responsável pela aquisição, transmissão e crítica do conhecimento cultural, possui pretensão de verdade. A segunda, denominada função interativa (atos regulativos), coordena as ações de pretensão de validade e respeito a normas vigentes reconhecidas intersubjetivamente. A terceira e última função a ser considerada denomina-se expressiva e deriva-se dos atos expressivos (sinceridade). Essa função permite formar a personalidade por meio da interação com pessoas e fixação das orientações de valores; capacita para agir com pretensão de validade e de veracidade.

Por isso a comunicação é tão importante na construção do conhecimento, pois a relação entre docente e aluno tornase uma relação de confiança, na qual é preciso que o docente seja verdadeiro naquilo que quer ensinar, para produzir no aluno mudança de atitude, o que consolidará esse conhecimento. Da mesma forma, o aluno deverá crer que o que o docente deseja "transmitir" possui pretensão de validade necessária para pensarem juntos esse conhecimento, de maneira que os atos de fala de um e do outro sejam evidenciados em suas atitudes.

De nada adianta o professor dizer que utilizará o agir comunicativo para construir o conhecimento e agir de maneira onipotente em sala de aula, com um discurso autoritário. Da mesma maneira, o aluno deve crer que o docente está-se esforçando para proporcionar-lhe a oportunidade de exercitar e expandir sua capacidade de compreensão, de reflexão, sua capacidade criativa. No entanto, para que o entendimento entre ambos seja alcançado, é preciso que suas atitudes obedeçam às normas de convivência social de respeito, oportunidade e solidariedade.

Outro aspecto importante na situação de entendimento são os níveis de comunicação a serem atingidos pelo falante e ouvinte ou seja, o nível comunicativo da intersubjetividade, no qual os sujeitos se falam. E o nível cognitivo, dos objetos, estados-de-coisas, pessoas, acontecimentos, proferimentos, sobre os quais os sujeitos procuram entender-se(6).

Se o cognitivo possibilita entendimento e a comunicação é onde se quer chegar, então a educação em enfermagem deve se desenvolver com base no agir comunicativo, no qual docentes e alunos estabeleçam uma harmonia entre suas atitudes.

Assim, será possível transpor aspectos técnicos, reducionistas da educação. A eficácia do agir comunicativo está baseada, no entendimento mútuo ${ }^{(5)}$. Dessa forma, estabelecem uma relação pautada na verdade, com a mensagem isenta de erro, legítima, em que a sinceridade seja manifesta por ambos.

Essa concepção remete a um profissional que interage com outros e vive seu processo de vida de forma a somar experiências que determinem um conhecimento elaborado com base no agir comunicativo.

Visualizar tecnologia, comunicação e sua inserção no saber no campo da Enfermagem, reforça a necessidade de unir teoria e prática, utilizar a tecnologia permeada pelo agir comunicativo. Da mesma forma os atos de fala em que verdade e veracidade sejam primordiais para o comprometimento da construção e inovação do saber.

Nesse contexto acreditamos que o agir comunicativo favoreça a formação de um profissional capaz de comunicarse, de atender às suas necessidades sociais de forma responsável, criativa e reflexiva, com sensibilidade e competência para ser um agente motivado a perceber o individual e o coletivo.

\section{Educação e conhecimento na enfermagem}

Se na educação, o indivíduo não deveria ser visualizado apenas como um receptor de informações, mas como um reavaliador crítico, então a educação não pode ser conceituada apenas como transmissão de idéias, mas como a redescoberta do indivíduo, suas capacidades, seus limites, de maneira a auxiliá-lo no desenvolvimento de suas capacidades.

A educação relaciona-se com cidadania, permeada pela competência construtiva (capacidade de reconstruir o conhecimento) e participativa (educação emancipatória). ${ }^{7}$

Instrução e informação sobre os saberes acumulados pela humanidade oferecidas pela escola são importantes, porém educar implica ir além da instrução informativa. Educar é reinventar e construir o conhecimento de forma personalizada, transpondo o mero preparo de mão-de-obra para o mundo globalizado, mas capacitando o profissional para ser um 
transformador da realidade ${ }^{(8)}$.

Afinal, só pode ser questionador o conhecimento que, primeiro, se questiona. Conhecer é o refazer permanente, o desafio de constante atualização, com base na capacidade de não só questionar, mas principalmente questionar-se ${ }^{(7)}$.

O docente, parceiro na busca pelo saber, possui a responsabilidade de acompanhar as transformações sociais e, ao mesmo tempo, educar com uma postura humilde de educador-aprendiz, consciente de que se aprende mais quando se ensina, e ensina-se mais quando se aprende, pois para isso é preciso ouvir, falar e respeitar.

A formação profissional exige pensar o significado de educador no preparo de futuros profissionais de Enfermagem, em um mundo com tantas mudanças complexas e desafiadoras $^{(9)}$.

O desenvolvimento das potencialidades humanas relaciona-se diretamente ao processo contínuo de troca de experiências e saberes dos quais participam atores sociais (docentes e alunos) que, mediados pelo agir comunicativo, geram questionamentos, suscitam investigação, promovem descobertas e favorecem criação e inovação desse conhecimento em prol do social. A construção do conhecimento, nessa perspectiva, é viabilizada pelo diálogo e valorização das relações interpessoais, na busca pelo entendimento, não se realizando com a mera explanação de idéias descontextualizadas da realidade e sim, na mudança de atitude de docentes e alunos na vivência das relações sociais e intercâmbio de experiências que possibilitem novas formas de pensar o saber e o fazer.

Mas, mesmo com o esforço coletivo na produção do conhecimento, se este não for socializado, gera-se uma situação de antidemocratização do saber, na qual a aprendizagem é considerada suficiente quando o aluno consegue reproduzir os ensinamentos que the foram transmitidos, como verdade única, sem questionar ou tentar inová-los. Embora aconteça de forma rápida, essa forma de "educação" distancia-se da proposta de educar para a cidadania. O saber permanece centrado no indivíduo para que, desprovido de significado, seja apenas reproduzido. A construção do conhecimento pede a escolha de uma metodologia de trabalho em que haja a união do conteúdo e da realidade do aluno. Além de evitar que o conhecimento seja fragmentado, respeita as diferentes culturas, pois cada indivíduo possui um mundo particular e uma forma de ver a realidade.

A educação vista como instrução, como padronização do saber, da maneira de pensar e de comunicar, tornou-se uma máquina de normalizar, fazendo com que haja um empobrecimento dos modos de pensar e de sentir(10).

Essa forma de conceber a educação tem feito com que a relação professor-aluno seja marcada por dúvidas: ao mesmo tempo que se educa para a autonomia, o aluno não consegue exercê-la. E por que isso ocorre? Quando se pensa que a educação deveria proporcionar ao aluno a libertação de seu poder de criação, da afirmação de sua personalidade e o desenvolvimento de novos saberes, ao mesmo tempo é possível deparar-se com uma educação em que reprodução do conhecimento e continuidade de práticas pedagógicas dominadoras impedem a conquista da autonomia. Mas, como mudar essas situação? Com certeza não existem fórmulas, mas o empenho em buscar alternativas para o ensino pode colaborar. O agir comunicativo faz parte desse empenho.

Afinal, educar é oportunizar diálogo e troca de experiências; é valorizar idéias, sem as quais a recriação e a transformação do conhecimento ficam ameaçadas e das quais a comunicação não pode estar dissociada, desde que favoreçam a produção do saber e sua socialização. Assim evitam-se as relações autoritárias, que reprimem a criatividade e a sensibilidade, dificultam a reflexão e permitem um ensino desconexo, perpetuando a dicotomia entre teoria e a prática.
Para que serve o conhecimento, então? O que fazer para que ele consiga ser protagonista para a autonomia e desenvolvimento social? A aquisição de um corpo de conhecimentos transmitidos na escola servem de base para agir no mercado de trabalho, estando apto a prestar serviços especializados em seu campo de atuação(11).

Em relação a esses serviços, afirma-se que o profissional não é aquele que apenas executa sua profissão, mas também àquele que sabe pensar e refazê-la ${ }^{(7)}$.

Mas, refazer ou recriar exige buscar alternativas didáticas que propiciem esse recriar. Na construção do conhecimento de Enfermagem, especificamente, o acesso à informação é importante, mas disponibilizar essa informação e buscar meios de favorecer a reflexão sobre ela é fundamental. Isso inclui desde seleção e elaboração de conteúdos, criação de metodologias de ensino e estudo centradas no aprendente e voltadas para a formação da autonomia, seleção dos meios mais adequados e produção de materiais, até criação e implementação de estratégias de utilização desses materiais e acompanhamento do estudante, de modo a assegurar a interação dele com novas tecnologias de ensino e aplicação do conhecimento no campo do trabalho.

Tendo em vista o exposto, o presente ensaio afetará positivamente as discussões sobre educação, comunicação e tecnologia, uma vez que traz uma nova abordagem ampliada para a construção do conhecimento a partir do agir comunicativo e, consequentemente, um repensar das práticas de ensino, rompendo com posturas cristalizadas e propiciando o emergir de novos horizontes para a profissão como um todo.

\section{Algumas considerações sobre o tema}

Atualmente não se pode mais admitir que a formação pedagógica, não considere o diálogo, o espaço para expor idéias e debater propostas. Sendo os cursos de Enfermagem, os espaços onde são formados os futuros profissionais, cabe a eles a responsabilidade de num esforço conjunto, implantar as Diretrizes básicas curriculares, a fim de que em parceria com o agir comunicativo, sejam capazes de utilizar a crítica e o pensamento reflexivo, para pensar a promoção da saúde enquanto responsabilidade de todos àqueles nela envolvidos.

Conforme mencionamos anteriormente, ao propormos o agir comunicativo na construção do conhecimento em Enfermagem, convidamos a pensar sua utilização como um diferencial entre a educação e a tecnologia.

Indagar nossa capacidade de conhecer constitui o oxigênio do conhecimento, para o alcance de oportunidades, felicidade e dignidade humana(12).

Não cabe à escola apenas formar trabalhadores para atender às necessidades do mercado, mas cidadãos com visão crítica, domínio das tecnologias e capacidade de atuação social consciente $^{(13)}$.

O agir comunicativo na produção do saber em Enfermagem promove mudanças a partir do conhecimento dos problemas que acometem os vários setores da sociedade e da investigação científica para solucioná-los. Quando isso ocorre, o indivíduo percebe sua importância e compromisso com a sociedade, demonstra autonomia e capacidade para resolver os problemas, o que caracteriza sua mudança de atitude, componente essencial nessa produção.

Conhecimento e ação estão articulados no processo educativo e, partindo da reflexão sobre cotidiano e práxis individual e coletiva, se constrói o conhecimento novo e a possibilidade de transformar a própria práxis ${ }^{(14)}$.

O saber-fazer consciente considera a necessidade do trabalho coletivo para mudar a prática, e é capaz de gerar conhecimento a partir de novas informações e vivências. Pensar a educação, num exercício coletivo de valorização das experiências e da criatividade individual, buscar novos instrumentos para o trabalho docente, aproximar o aluno da 
O agir comunicativo na construção...

realidade do trabalho, convergindo a teoria à prática, pode contribuir com a formação de um profissional crítico, com capacidade de criar e recriar.

Assim, o agir comunicativo pode também suscitar a crítica, a inovação e a reflexão necessárias para que o convívio dialógico possibilite a construção do conhecimento. Aliado às tecnologias educacionais, poderá auxiliar a Enfermagem a transpor dificuldades, produzir e compartilhar saberes. Visualizar o agir comunicativo como mediador entre as tecnologias educacionais e a construção do conhecimento, consiste em compreender as implicações da educação sobre a formação profissional.

Essa formação profissional, não se dá isoladamente mas sim, entrelaçada; todos tem sua importância e tornam-se essenciais. Deve-se compreender este processo de capacitação do indivíduo, como dinâmico e em constante avaliação. Somente desta forma será possível inovar no campo das competências da Enfermagem.

\section{Referências}

1. Alves ED. O agir comunicativo e as propostas curriculares da enfermagem brasileira. Pelotas (RS): Universitária/UFPel; Florianópolis (SC):UFSC;2000.199p.

2. Vieira L. Cidadania e globalização. Rio de Janeiro: Record; 1997. $142 \mathrm{p}$.

3. Collière M F. Promover a vida: da prática das mulheres de virtude aos cuidados de Enfermagem. Lisboa: Printipo;1989.385p.

4. Nascimento SR. A educação tecnológica no processo de ensinoaprendizagem das técnicas de enfermagem [dissertação de mestrado em tecnologia]. Curitiba (PR) : Centro Federal de Educação Tecnológica do Paraná;1998.95p.
5. Habermas J. Consciência moral e agir comunicativo. [tradução de Guido Almeida]. Rio de Janeiro: Tempo Brasileiro;1989.236p.

6. Siebeneichler FB. Jürgen Habermas: razão comunicativa e emancipação. $3^{a}$ ed. Rio de Janeiro: Tempo Brasileiro;1994.181p.

7. Demo P. Combate à pobreza. Desenvolvimento como oportunidade. Campinas: Autores Associados;1996.212p.

8. Assman $\mathrm{H}$. Reencantar a educação. Rumo à sociedade aprendente. Petrópolis (RJ): Vozes;1998.251p.

9. Waldow VR. Desenvolvimento do pensamento crítico na enfermagem. In: Waldow VR, Lopes MJM, Meyer DE. Maneiras de cuidar. Maneiras de ensinar. A enfermagem entre a escola e a prática profissional. Porto Alegre (RS): Artes Médicas;1995.203p.

10. Perrenoud $P$. Ensinar: agir na urgência, decidir na incerteza [tradução Claudia Schilling]. Porto Alegre (RS): Artmed;2001.208p.

11. Machado MH. A profissão de enfermagem no século XXI. Revista Brasileira de Enfermagem, Brasília (DF); 1999 out/dez;52(4):589595.

12. Morin E. Os sete saberes necessários à educação do futuro. $3^{\mathrm{a}}$ ed. São Paulo: Cortez;2001.118p.

13. Sampaio MN, Leite LS. Alfabetização tecnológica do professor. Petrópolis (RJ): Vozes;1999.111p.

14. Ramos FRS, Verdi MM, Kleba ME. Para pensar o cotidiano: educação em saúde e a práxis da enfermagem. Florianópolis (SC): UFSC;1999. $163 p$.

Data de Recebimento: 08/12/2003

Data de Aprovação: 28/06/2004 